\title{
BMJ Open Enhancing Social Interaction in Depression (SIDE study): protocol of a randomised controlled trial on the effects of a Cognitively Based Compassion Training (CBCT) for couples
}

Corina Aguilar-Raab, ${ }^{1}$ Marc N Jarczok, ${ }^{1,2}$ Marco Warth, ${ }^{1}$ Martin Stoffel, ${ }^{1}$ Friederike Winter, ${ }^{1}$ Maria Tieck, ${ }^{1}$ Judith Berg, ${ }^{1}$ Lobsang Tenzin Negi, ${ }^{3}$ Tim Harrison, ${ }^{4}$ Thaddeus W W Pace, ${ }^{5,6,7}$ Beate Ditzen ${ }^{1}$

To cite: Aguilar-Raab C, Jarczok MN, Warth M, et al. Enhancing Social Interaction in Depression (SIDE study): protocol of a randomised controlled trial on the effects of a Cognitively Based Compassion Training (CBCT) for couples. BMJ Open 2018;8:e020448. doi:10.1136/ bmjopen-2017-020448

- Prepublication history and additional material for this paper are available online. To view these files, please visit the journal online (http://dx.doi org/10.1136/bmjopen-2017020448).

CA-R and MNJ contributed equally.

Received 7 November 2017

Revised 24 May 2018

Accepted 21 June 2018

Check for updates

(c) Author(s) (or their employer(s)) 2018. Re-use permitted under CC BY-NC. No commercial re-use. See rights and permissions. Published by BMJ.

For numbered affiliations see end of article.

Correspondence to Dr Corina Aguilar-Raab; corina.aguilar-raab@med.uniheidelberg.de

\section{ABSTRACT}

Introduction Positive social interactions (PSIs) and stable relationships can exert substantial benefits on health. However, patients suffering from depression benefit less from these health-promoting effects. Moreover, relationship quality and even partners' health has been found to be negatively affected by depressive symptomatology, which may result in overall impairments in social functioning of a romantic couple. Psychobiological research indicates that these impairments may be accompanied by a maladaptive regulation of the patient's neuroendocrine response to external stressors. Concerning the improvement of social functioning, first studies showed promising results of "Cognitively Based Compassion Training (СBCT囚)". However, randomised trials are still scarce. Previous programmes did not involve participation of the patient's romantic partner. Therefore, the present study aims to investigate whether a СBCT® programme adapted for couples (CBCT $囚$-fC) can improve depressive symptoms, distress, social interaction skills and the neurobiological regulation of stress.

Methods and analysis Couples with the female partner suffering from depression will be invited to participate in a pre-to-post intervention assessment on two consecutive days, respectively, involving a standardised PSI task, eye-tracking, ECG recordings, saliva-sampling, blood-sampling and questionnaire data. After baseline assessment, participating couples will be randomised to either a 10 week $\mathrm{CBCT}$ - $\mathrm{fC}$ or to a treatment as usual control condition. The primary endpoint is the reduction of depressive symptoms measured by the Hamilton Depression Rating Scale. Secondary outcomes encompass self-rated depression (Beck Depression Inventory), attention towards the partners face during PSI (eye tracking), stress-related biomarkers (cortisol, $\alpha$-amylase, interleukin (IL)-1B/LL-6, heart rate variability), methylation of oxytocin-receptor-genes and serotonin-transportergenes and self-ratings of psychological constructs such as relationship quality and empathy.

Ethics and dissemination Ethical approval has been obtained by the Ethics Committee of the Medical Faculty Heidelberg. Results will be presented in international,
Strengths and limitations of this study

- This is the first randomised controlled trial to investigate the effects of a group-based compassion meditation programme for couples ("Cognitively Based Compassion Training for couples (CBCT-fC)").

- We focus on females suffering from depression.

- The study employs novel methods, assessing positive real-time social interaction of romantic partners in combination with psychobiological indicators of health.

- Several processes previously reported to be involved in the aetiology and basic mechanisms of social functioning that are part of the psychopathology of depression are investigated simultaneously.

- Comparison with treatment as usual control group does not allow one to draw conclusions about the specificity of CBCT-fC.

peer-reviewed journals and on conferences in the field of clinical psychology and psychiatry.

Trial registration number NCT03080025.

\section{BACKGROUND}

Depression is one of the most prevalent mental disorders worldwide. ${ }^{1}{ }^{2}$ Besides changes in self-referential affect and cognition, depressive disorders have been associated with social deficits. Impaired social functioning of depressive patients could account for both a worsening of the illness to chronic levels and for a generally degraded physical health status, which in turn, may be accompanied by severe alterations of the biological stress and immune systems. ${ }^{13}$ It is crucial to examine how depressive patients' impaired social functioning maintains and/ or aggravates the overall impact of the illness and how disease progression interacts with 
the close social environment around a patient, in particular with the supportive partner. ${ }^{4}$

\section{Impaired social functioning in depression}

Positive social interactions (PSIs) can exert substantial benefits on health and even survival rates of individuals. ${ }^{35}$ For the majority of adults, couple relationships represent the central social bond and are the main source of social support. ${ }^{6}$ However, patients with chronic mental illnesses, such as depression, seem to benefit less from these health-protective effects. Current research has shown a bidirectional association between depression and relationship quality. ${ }^{7}$ Problematic relationships may reinforce depressive symptoms in the romantic partners. However, depression and subsequent deficiencies in social functioning are strongly associated with a decrease in marital quality. ${ }^{89}$ Consequently, depression also affects the romantic partner and his/her health. ${ }^{10}$

The incapacities for those with depression to socially connect and affiliate with others might lead to a tendency for social withdrawal and non-approaching behaviour. Depressed individuals tend to be afraid of social rejection and the subsequent negative emotions and expect less support and kindness from others. ${ }^{11}$ This may be accompanied by a reduced capacity to adaptively engage in social interaction and communication and a diminished ability for empathic accuracy and perspective taking. ${ }^{12}$

Underlying this, depressed individuals have been found to exhibit biased information processing including a distorted attention for social stimuli. ${ }^{13}$ Hence, impaired processing and attentional disengagement from negative self-referencing information take place, that is, reduced maintenance of gaze towards positive stimuli, and in contrast, increased maintenance of gaze towards negative stimuli. ${ }^{14} 15$ It is likely that this biased cognitive information processing may transfer to marital interaction as well.

\section{Psychobiological underpinnings}

While more research is still needed in order to understand how social-cognitive processes in couples may affect physical health outcomes, ${ }^{7}$ it seems consistent that severe or chronic depression is associated with alterations in the psychobiological stress and immune systems, including cortisol, ${ }^{16}{ }^{17}$ alpha-amylase (sAA), ${ }^{18} 19$ vagally mediated heart rate variability $(\mathrm{vmHRV})^{20}$ and proinflammatory cytokine regulation (interleukin (IL)-6 and IL-1B and high sensitive $\mathrm{C}$ reactive protein). ${ }^{21}$ Additionally, stress-associated alterations of methylation patterns in the gene encoding the serotonin transporter activation (SLC6A4) have been found in patients with depression. ${ }^{22}$

Maladaptivealterationsin the hypothalamic-pituitary-adrenal (HPA) system's response to chronic stress have been proposed as a potential pathophysiological mechanism in the development of depressive disorders, with dysregulation of glucocorticoid release (in particular cortisol) being one of the most frequently studied phenomena. ${ }^{23} 24$ Changes in the diurnal rhythms of cortisol release may in part be responsible for disordered circadian physiology involving sleep patterns and body temperature rhythms. Increased levels of morning cortisol may be a risk factor for subsequent depression. ${ }^{162}$ Moreover, a meta-analysis by Stetler and Miller found higher basal cortisol levels in depressed individuals. ${ }^{26}$ Similar, depressed versus healthy individuals showed elevated cortisol release in response to acute psychosocial stress challenge. ${ }^{17}$ The magnitude and direction of these cortisol effects, however, were found to be strongly dependent on moderating variables such as methodological quality, type of cortisol assessment, sex, measurement time or type of stress task. ${ }^{17} 26$ In particular, women with remitted depression showed a blunted cortisol response to a psychologically stressful task compared with healthy controls, while cortisol reactivity was increased in depressed men. ${ }^{27}{ }^{28}$ Together these findings suggest that more research is needed, although there is evidence for HPA-axis dysregulation in major depression.

Concerning the human stress response, the HPA axis interacts with the autonomic nervous system (ANS) in the context of both acute and chronic stress challenge situations. Recent studies highlight the importance of monitoring both systems simultaneously, in order to gain a better understanding of the pathophysiological mechanisms involved with depression. ${ }^{18}$ Available evidence suggests that acute stress is related to higher momentary salivary alpha-amylase (sAA) activity. sAA is an enzyme mainly secreted by the parotid glands in response to adrenergic innervation and has been studied as a proxy for the sympatho-adreno-medullary (SAM) branch of the ANS. sAA stimulation may involve activation of further physiological subsystems (eg, parasympathetic fibres) ${ }^{29}$ and prior studies suggest that acute sAA changes may reflect ANS dysfunction in patients with mental disorders. ${ }^{19}$ Furthermore, sAA secretion has been associated with depression and feelings of shame. ${ }^{30}{ }^{31}$ In addition, sAA levels have been found to be significantly higher before and after an electrical stimulation stressor in depressed individuals than in healthy controls. ${ }^{28}$ While some authors have raised issues about the validity of sAA as a biomarker of SAM activation, ${ }^{29}$ others highlight the potential of sAA to monitor SAM along with HPA activity in saliva (instead of in blood). ${ }^{18} 1930$

Previous research investigating the involvement of the parasympathetic branch of the ANS in the pathophysiology of depression has focused mainly on the study of vmHRV. Compared with healthy individuals, depressed patients have been found to exhibit parasympathetic withdrawal, and prior studies have reported a negative association between depressive symptoms and resting state short-term measures of vmHRV. ${ }^{20}{ }^{32}$ In contrast, higher levels of sadness have been associated with increased circadian variation of vmHRV measures, but only in females. ${ }^{32}$ Similarly, we investigated the circadian variation pattern (CVP) by mild depressive symptoms in a large, rather healthy occupational sample. Depressive symptoms were found to be negatively associated with the 24hours mean (Midline Estimating Statistic of 
Rhythm (MESOR)) and oscillation amplitude in men but positively associated in women. This pattern of findings indicates a blunted day-night rhythm of vagal activity in men with greater depressive symptoms as well as a moderation effect of sex in the association of CVP and depressive symptoms. ${ }^{33}$ Moreover, we have shown in a study with non-human primates that greater amounts of depressive-like behaviour is associated with elevated levels of vmHRV in adult female cynomolgus monkeys (Macaca fascicularis). ${ }^{34}$ We believe that this finding is evidence of a cross-species psychophysiological alterations of heart rate variability in depression.

Stress-related chronic HPA-axis and ANS dysfunctions can promote the release of cytokines from the macrophages, resulting in symptoms of fatigue and loss of appetite. $^{2135}$ Depressed patients exhibit higher circulating concentrations of proinflammatory cytokines, particularly IL- 6 and IL-1B, which were found to be indicative of a non-specific immune response (ie, without an identifiable pathogen or injury to tissues).$^{36}$ In line with these findings, administration of cytokines in animal models and humans results in behavioural symptoms that are common in depression, such as depressive mood or slowed psychomotor activity. ${ }^{21}$

The vulnerability for depression-especially with regard to early adversity-is also believed to involve genetic factors, in combination with environmental exposure across the lifespan. Gene-environment interactions have been found to alter the risk for the development of major depression. Altered gene expression is rooted in changes in chromatin structure, and alterations in these epigenetic marks are connected to depression. ${ }^{38}$ Changes in methylation in the promoter of the serotonin transporter gene SLC6A4 have been focused in several studies investigating depression. For example, decreased methylation of SLC6A4 has been found in stress-exposed shift-working nurses and was also related to burnout. ${ }^{39}$ However, in contrast, increased methylation was described in depressed patients with low quality of life and functioning. ${ }^{22}$ These diverse findings may be due to the analysis of different Cytosin-phosphatidyl-Guanin or CpG sites in each study. ${ }^{38}$ Thus, while overall methylation of serotonin transporter genes and their expression seem significantly associated with the reactivity of HPA-axis and ANS in depression, ${ }^{40} 41$ the precise direction of each specific alteration in the related CpGs needs further investigation. In accordance with SLC6A4 data, oxytocin receptor gene (OXTR) methylation patterns have been associated to neural activity to the perception/cognition of social stimuli ${ }^{42}$ and relationship functioning. ${ }^{43}$ In previous studies, interpersonal functioning-like rejection sensitivity or less support seeking, which is predominant in depressed individualswas linked to OXTR gene polymorphisms. ${ }^{44}$ To date, it remains unclear whether serotonin or oxytocin related epigenetic processes underlie alterations of interpersonal functioning in depression and might be interpreted as evaluation criteria for therapy. For example, SLC6A4 methylation has been associated with the responsiveness of patients to pharmacological anti-depressive treatment, and treatment with selective serotonin reuptake inhibitors has been found to result in higher levels of methylation of SLC6A4 ${ }^{45}$ and lower levels of methylation in neuroblastome cells treated with quetiapine. ${ }^{46}$ Besides pharmacologically induced alterations in epigenetic patterns, a new area in psychiatric research suggests that epigenetic mechanisms are involved in psychopathology and in the development of resilience ${ }^{47}$ and responsiveness of patients with mental disorder to behavioural interventions. ${ }^{48}$ Within this framework, SLC6A4 methylation has been shown to be increased in individuals with social anxiety, but only those who respond to cognitive behavioural therapy. ${ }^{49}$ In addition, the severity of depressive symptoms has been shown to be associated with levels of SLC6A4 methylation, ${ }^{50}$ indicating a covariation of the two. These findings also suggest that SLC6A4 methylation may be susceptible to change as a result of interventions that target depressive symptoms.

\section{Mindfulness, compassion and compassion-based interventions}

Mindfulness is defined as the intentional directing of attention towards the present moment, combined with an attitude of acceptance and non-reactivity. ${ }^{51-53}$ Mindfulness can be trained and increased through sustainable exercise, such as breathing meditation. It is associated with coping-strategies in achieving a healthier or better handling with the inner stress-response towards perceived stressors.

Subsequent to the successful implementation of the Mindfulness-Based Stress Reduction (MBSR) programme,${ }^{54-57}$ more scrutiny has been placed on understanding the mechanisms of how mindfulness promotes positive change for greater well-being. In a recent study, we could show that enhanced mindfulness as a result of MBSR participation is accompanied by two other important health-related psychological constructsdistress tolerance and resilience. ${ }^{58}$ In addition to other refined and revised approaches, such as the Mindfulness-Based Cognitive Therapy, ${ }^{59}$ current research in the field of 'contemplative science has begun to focus more on compassion and interventions such as the "Cognitively Based Compassion Training (CBCT)" ${ }^{61-63}$ The definition of compassion highlights social aspects explicitly: In addition to the competency to recognise sorrowful states, compassion includes the prosocial motivation to deal with determining factors of suffering and to contribute to their change. ${ }^{64}$

Secular meditation trainings that address loving kindness and compassion can enhance positive emotions and social support, which are associated with perceived social connectedness. ${ }^{6566}$ Furthermore, they can lead to faster cortisol recovery subsequent to a social stress test as well as reduced responsiveness of inflammation to psychosocial stress. ${ }^{67}$ However, studies (either laboratory or intervention) shedding light into the interplay between psychological and biological factors are still rare. 
Mindfulness has already been successfully integrated into the context of couples, such as mindfulness-based relationship enhancement, ${ }^{68}$ and improving relationship satisfaction and functioning. ${ }^{68-70}$ As far as couples are concerned, no study has yet investigated the impact of compassion enhancement on aspects of relationship quality. Current findings suggest that strong connections may be found between self-compassion and aspects of healthy interpersonal relationship functioning such as increased caring, kindness and higher levels of relatedness. ${ }^{71}$ Moreover, higher self-compassion has been positively associated with compromise behaviour in the context of romantic relationships. ${ }^{72}$ Given this background, we believe the application of compassion training to depressive patients with impairments in interaction skills and their partners is a promising approach. Moreover, a group-based couple intervention additionally takes into account the partner's needs and may therefore provide a better integration of intervention benefits into patient couples' daily life.

We therefore adapted a group-based compassion meditation training programme (see below) for couples, intending to improve social interactional functioning in couples where one member of the dyad is diagnosed with depression. The project will also work in a preliminary manner to determine if the compassion meditation training programme is associated with positive change in psychobiological indicators of health, as well as decreases in the severity of depression features.

\section{Objectives}

The proposed study aims to evaluate whether a CBCT intervention for couples (CBCT -fC), with the female partner suffering from depression, can:

1. reduce depressive symptoms in the female partner,

2. improve social cognition processes and interpersonal skills of the female partner and

3. reduce stress reactivity (measured as cortisol, sAA and markers of inflammation) to social interactions in both partners that is associated with alterations in methylation patterns of SLC6A4 and OXTR.

We expect the improvement of couples participating in CBCT-fC to be superior compared with those receiving treatment as usual (TAU).

\section{METHOD}

\section{Study design}

This study will be conducted asa prospective, parallel randomised controlled trial (RCT), comparing CBCT-fC with a TAU control condition. Changes in outcome measures from baseline (T1 at weeks 8-10 after recruitment start); to postintervention assessment (T2 weeks 20-21 after recruitment start); to follow-up 4 week postintervention (FU1 week 24-25) and to 12-week follow-up postintervention (FU2 weeks 33-34) will be compared between the two study arms (figure 1). Data assessment and interventions will be carried out at the Institute of Medical Psychology (IMP), Center for Psychosocial Medicine, University Hospital Heidelberg, Germany. The IMP will provide the laboratory infrastructure for biomarker analysis (freezer space, centrifuge) and therapy rooms equipped with audio and video devices for presentations/ exercises and assuring intervention adherence.

\section{Recruitment}

We will use the following sources to recruit participants: Newspaper advertising, posters and flyers in public places, advertising in public transport, advertising in social media and university mailing lists. We will additionally contact registered doctors, psychiatric and psychosomatic clinics as well as outpatient centres for counselling and psychotherapy. The enrolment of the first depressed couple has started on 28 March 2017.

\section{Participants}

The study described here focuses primarily on females due to several reasons: Current prevalence rates of major depression indicate that females are affected twice as often as men; there also seem to be some differences in the phenomenological symptomatology. Additionally, as the study focuses on psychobiological markers and as there are hormonal differences in women and men, and for financial and infrastructural (feasibility) reasons, we had to keep the sample size manageable.

Female patients are included if they (1) are at least 20 years old, (2) have a romantic relationship for at least 2 years and (3) are diagnosed with a primary recurrent depressive disorder (ICD-10: F33.0 or F33.1) by the Structured Clinical Interview (SCID) of the Diagnostic



Figure 1 Study design. CBCT-fC, "Cognitively-Based Compassion Training" for couples; FU1/2, follow-up 1 and 2; PSI, positive social interaction; TAU, treatment as usual; T1, measurement point 1 (baseline); T2, measurement point 2 (postintervention). 
and Statistical Manual of Mental Disorders (DSM-V) ${ }^{73}$ in combination with the observer-based Hamilton Depression Rating Scale (HDRS $\geq 12$, within the range of a mild depression) ${ }^{74}$ and the Beck Depression Inventory (BDI$\mathrm{II} \geq 16$, within the range of mild depression) self-rating. ${ }^{\text {. }} 7576$ General exclusion criteria for the female patients are: (1) other severe mental disorders (such as psychotic symptoms; bipolar disorders, acute suicidal tendency), (2) altered physical condition (pregnancy, chronic or severe metabolic, endocrinological, neurological, nephrological, cardiac or hepatic conditions), (3) heavy smoking ( $\geq 20$ cigarettes/day), substance abuse or acute addiction, (4) enrolling in psychological therapies (couple therapy; individual psychotherapy-except for probatory phase including a maximum of the first six sessions) and (5) current participation in a mindfulness-based or compassion-based group training.

Male partners are included if they (1) are at least 20 years of age, (2) have a romantic relationship for at least 2 years (with the targeted depressed female partner) and (3) are not diagnosed with a primary recurrent depressive disorder (ICD-10: F33.0 or F33.1) by the SCID of the DSM-V. ${ }^{73}$ General exclusion criteria for the male patients are primarily with regard to acute mental disorders at baseline not life span: (1) other severe mental disorders (such as psychotic symptoms; bipolar disorders, acute suicidal tendency), (2) altered physical condition (chronic or severe metabolic, endocrinological, neurological, nephrological, cardiac or hepatic conditions), (3) heavy smoking ( $\geq 20$ cigarettes/day), substance abuse or acute addiction, (4) enrolling in couple therapy and (5) current participation in a mindfulness-based or compassion-based group training.

\section{Patient and public involvement}

Overall, the patients are neither involved in the design nor in recruitment or conduction of the study. In a piloting phase, we tested all the materials, questionnaires and laboratory assessments. Due to the participants' experience and feedback, we reduced the quantity of questionnaires, changed the procedure of the surveys and laboratory/psychobiological assessments in order to significantly reduce the effort and expense. With regard to the RCT design, we ask each participant to evaluate study-related measures, design and the intervention itself. All participants will receive the published articles with the final results of the study, and a short summary of the major findings will be provided in an email.

\section{Procedures}

\section{Baseline assessment (T1)}

After confirming eligibility of both members of a couple in initial and separate telephone screenings, couples will

\footnotetext{
${ }^{\mathrm{i}}$ The cut-off scores for the HDRS German version are defined as follows: $\leq 8=$ normal $/$ remitted; $9-16=$ mild; $17-24=$ moderate; $\geq 25$ severe depression and for the BDI-II German version: $\leq 13=$ normal $/$ remitted; 13-19=mild; $20-28=$ moderate; $\geq 29$ severe depression. These cut-off scores are defined by the S3-guidelines of the Working Group of the Scientific Medical Societies of Germany. ${ }^{76}$
}

be invited to two consecutive laboratory days. On lab day 1 , we will inform the participants about the study goals and procedures and ask them to complete the informed consent form. Participants will then be interviewed to complete the SCID and HDRS observer rating to assess for the presence of mental (particularly depressive) disorders. While one partner is interviewed, the other will be asked to fill out a series of questionnaires including the BDI-II and several scales on relationship quality, empathy and symptom burden (see table 1). Afterwards, a medical assistant will take blood samples from both partners of approximately $25 \mathrm{~mL}$ each, using EDTA Vacutainers and PAXgene Blood RNA Tubes, allowing for the analysis of immune and epigenetic parameters. The genes SLC6A4 and OXTR will be analysed for methylation of CpG-sites and their promoter-regions, referring to polymorphisms and mRNA-expression. Blood samples will be stored in the IMP's biochemical laboratory and will then be transferred to the Central Institute of Mental Health in Mannheim, Germany and to the Central Laboratory at Heidelberg University, for further analyses. After blood sampling, each individual will be fitted with a one-lead ambulatory ECG monitor (eMotion FAROS $180^{\circ}$ ) for 24 hours recording. Participants will also be instructed in the handling of the device.

Lab day 2 will take part in our eye-tracking laboratory (IMP Heidelberg), where participating couples will be comfortably seated facing each other, with a table in between serving as the eye-tracking platform. The first saliva sample will be taken after welcoming the participants. We will then calibrate the eye-tracking system. A scene camera will be placed next to the women's head/ eyes to capture her gaze perspective (ie, the view on her partner). The arrangement of all eye-tracking and related equipment is pictured in the online supplementary appendix 1. Gaze direction and fixations points will be recorded with a TOBII XT 60 remote eye-tracking device at $60 \mathrm{~Hz}$ and mapped to the picture captured by the scene camera. Regions of interest are segmented into: partner's eyes, mouth, rest of the face and off-face area.

We will then provide participants with instructions for the PSI: first, each person will receive a list of 27 standardised conversation topics and will be asked to choose topics they wish to discuss, in whatever order is fitting for a particular couple. Topics were adopted from the Problem List used in research on relationship conflict, ${ }^{77}$ but modified so that the conversational focus is on positive, instead of negative, issues (eg, trust, financial security and affection). Couples will be verbally instructed to exclusively talk about positive content, to be supportive, to express compliments towards each other. As soon as couples 'fall of track' of the discussion, they will be asked to continue with another topic. Conversations will be videotaped and checked for protocol adherence. The experimenter will then leave the room, and participants will perform the PSI for a duration of $10 \mathrm{~min}$. Before and after the PSI, the second and third saliva samples will be taken and couples will fill out a 9-item self-constructed 
Table 1 Overview of measures

\begin{tabular}{|c|c|c|c|c|}
\hline Short name & Full name & $\begin{array}{l}\text { Pretreatment } \\
\text { (CBCT-fC vs TAU) }\end{array}$ & $\begin{array}{l}\text { Post-treatment } \\
\text { (CBCT-fC vs TAU) }\end{array}$ & Comments \\
\hline \multicolumn{5}{|l|}{ Primary outcomes } \\
\hline \multicolumn{5}{|l|}{ Secondary outcomes } \\
\hline BDI-II & Beck Depression Inventory ${ }^{75}$ & $X$ & $\mathrm{X}$ & \\
\hline$E Q$ & Empathy Quotient & $x$ & $x$ & \\
\hline EVOS & Evaluation of Social Systems Scale ${ }^{117118}$ & $X$ & $x$ & \\
\hline UCLA-LS & $\begin{array}{l}\text { UCLA-Loneliness-Scale }{ }^{119} \text { (German } \\
\text { version: Hamburger Einsamkeitsskala }{ }^{120} \text { ) }\end{array}$ & $\mathrm{X}$ & $X$ & \\
\hline PFB & Partnership Questionnaire ${ }^{123}$ & $\mathrm{X}$ & $x$ & \\
\hline PHQ-9 & Patient Health Questionnaire ${ }^{124125}$ & $x$ & $x$ & \\
\hline RAS (Item 2) & $\begin{array}{l}\text { Second Item from the Relationship } \\
\text { Assessment Scale }\end{array}$ & $x$ & $x$ & \\
\hline SCS & Self Compassion Scale $e^{71127}$ & $x$ & $X$ & \\
\hline TICS & Trier Inventory for chronic Stress ${ }^{128}$ & $\mathrm{X}$ & $\mathrm{X}$ & \\
\hline \multicolumn{5}{|c|}{ Characteristics and confounders } \\
\hline CLE & Critical Life Events & $x$ & $x$ & \\
\hline \multicolumn{5}{|l|}{ Checklists } \\
\hline $\begin{array}{l}\text { Checklist for blood } \\
\text { samples }\end{array}$ & $\begin{array}{l}\text { eg, medication in the last } 24 \text { hours, } \\
\text { alcohol, etc }\end{array}$ & $x$ & $x$ & \\
\hline Checklist for ECG & eg, quality of sleep, pain, etc & $\mathrm{X}$ & $x$ & \\
\hline $\begin{array}{l}\text { Checklist for Saliva } \\
\text { sample }\end{array}$ & $\begin{array}{l}\text { eg, medication in the last } 24 \text { hours, } \\
\text { alcohol, etc }\end{array}$ & $X$ & $X$ & \\
\hline
\end{tabular}

scale on acute mood. During the PSI, eye-tracking data of the female partner will be continuously recorded. We will collect the fourth saliva sample 20 min after the PSI. During the waiting time and until discharge, participants will be asked to complete a second set of questionnaires and to return the ECG devices. Procedures and assessments are summarised in figure 2. A participant flowchart can be found in figure 3 .

For all salivary samples, we will use SaliCab tubes (RE69985 IBL International GmbH Hamburg, Germany) with the passive drool method. After collection, the samples will be immediately stored at $-80^{\circ} \mathrm{C}$. Cortisol and $\alpha$-amylase will be batch assayed later at the in-house laboratory of the IMP.

Postintervention assessment (T2)

After the baseline assessment (T1) is completed, couples will be invited to participate in the training programme or to continue their routine care plan for a duration of 10 weeks. After the interventional period (description see 


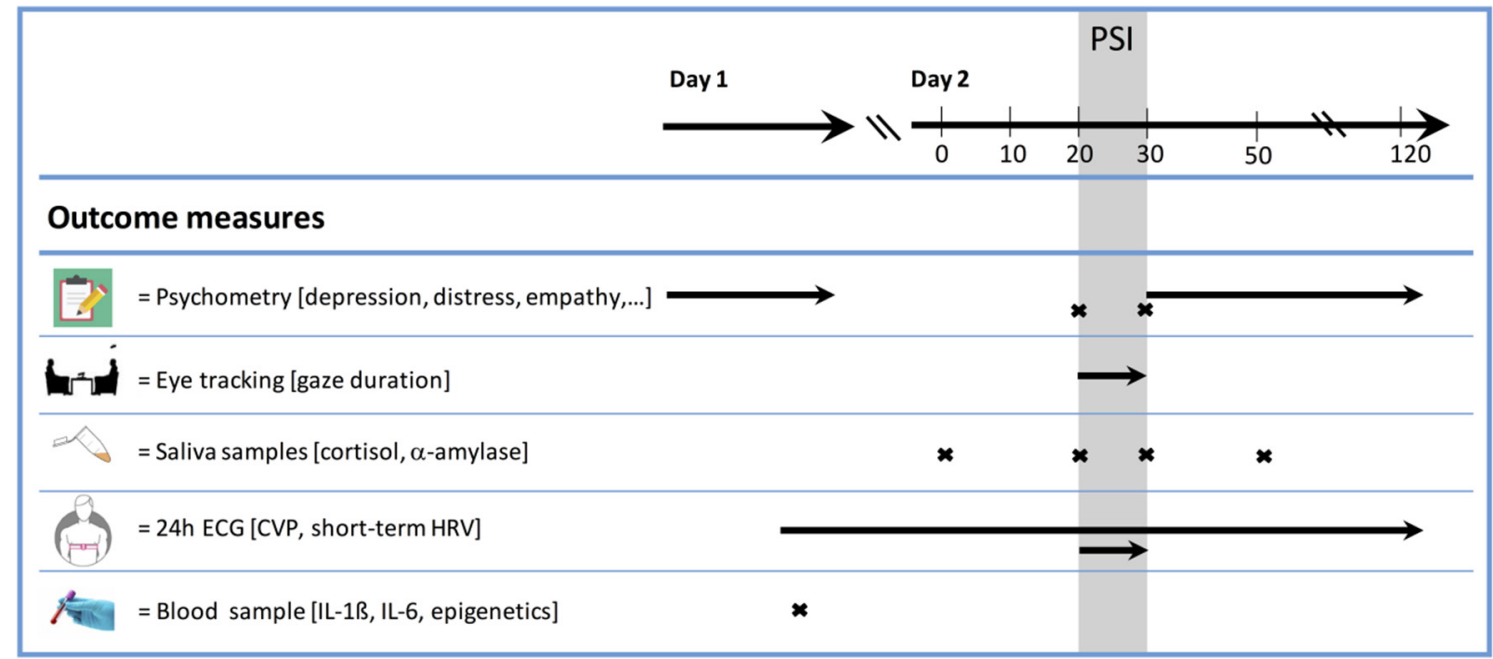

Figure 2 Assessments. CVP, circadian variation pattern; HRV, heart rate variability, IL, interleukin; PSI, positive social interaction.

below) is completed, participants will undergo all assessments described above except for the SCID interview at T2.

\section{Follow-up assessments (FU1 and FU2)}

Two follow-up assessments (FU1 and FU2) will be conducted in both the CBCT-fC and TAU control group. Four and 12 weeks after completion of the training (FU1: weeks 24-25; FU2: 33-34), the questionnaires administered at baseline will be distributed to participants online (see table 1). In case participants are lost to follow-up, theywill be contacted and asked to state reasons they discontinued participation in order to enable us to perform appropriate missing data analysis and interpretation of data.

\section{Blinding and randomisation}

A portion of the study personnel will be blinded about allocation of couples to either treatment group (CBCT-fC or TAU), including the medical staff conducting the blood draw, all wet lab personnel and all research assistants performing the eye tracking assessment. All participants will be informed about the general aims of the study. However, participants will not be informed about the operationalisations of behavioural and biological measures.

Couples will be block-randomised to either CBCT-fC or control group using a computerised random-number generator (http://www.random.org). Blocks for each study cohort (consisting of at least eight couples) will be randomised after recruitment and baseline assessments are completed. This randomisation procedure will be repeated until the planned number of participating couples is reached. A postdoctoral researcher of the IMP, who is otherwise not involved in the proposed study, will conduct all randomisation for the study. Figure 3 depicts the CONSORT flowchart ${ }^{78}$ of the present study.

\section{Interventions}

All participants (including those randomised to CBCTfC) will receive the standard treatment (TAU) for depression. All treatments, including prescriptions, will be monitored for both groups. At a minimum, this monitoring will include general practitioner care and contact with community mental health providers.

\section{CBCT-fC—Cognitively Based Compassion Training for couples}

CBCT is a secular approach and was established as a structured protocol consisting of an either 6-week, 8-week or 10-week training programme with a 1.5-2-hour group session weekly and daily home practice based on prerecorded guided meditations of $7-20 \mathrm{~min}$ for at least 3 days a week. ${ }^{61}$ In this study, we will implement a 10 -week training programme with 2-hour weekly sessions, including class teachings explaining and discussing the rationale of the content of each of the six modules, group discussions and individual and dyadic-guided contemplative practices. The text of the audio-based daily home practice is standardised and for the purpose of this study translated and audio-recorded into German by the same certified instructor who will also lead the CBCT-fC groups (CAR).

The trainer (CAR) is a certified couple and a family therapist and is in an advanced stage of individual psychotherapy training. She is currently conducting individual psychotherapy under supervision and has already acquired clinical experience with the treatment of psychiatric and psychosomatic disorders. She is also fulfilling several training requirements, such as long-term practice of mindfulness-based and compassion-based meditation, under guidance of recognised supervisors and meditation teachers (LTN and others). She has also attended the CBCT Teacher certification programme at Emory University (Atlanta, USA).

For CBCT, all human beings are considered to be endowed with a biologically based compassion that is focused on those close to us. But as research has shown, 
telephone pre-screening of study-participants, overall study information

\begin{tabular}{|c|c|c|}
\hline \multicolumn{3}{|c|}{$\begin{array}{l}\text { Day } 1 \text { T1: informed consent }+ \text { baseline assesment } \\
\text { - } \text { HDRS, BDI-II, SCID } \rightarrow \text { diagnosis } \\
\text { - } \quad \text { other psychometric measures (e.g. relationship quality) } \\
\text { - } \text { Blood collection } \\
\text { - }\end{array}$} \\
\hline & & Inclusion \\
\hline \multicolumn{3}{|c|}{$\begin{array}{l}\text { Day } 2 \text { T1: Laboratory assessment, positive social interaction (PSI) } \\
\text { - Eye-tracking, video-recording } \\
\text { - } \quad \text { Saliva samples } \\
\text { - } \quad \text { Psychometric measures } \\
\text { - } \text { End of } 24 \text { hours ECG recording } \\
\end{array}$} \\
\hline \multicolumn{3}{|c|}{ Stratified block randomization ( $\mathrm{N}=50$ couples) } \\
\hline $\begin{array}{c}\text { TAU }+ \text { CBCT } ®-f C \\
\mathrm{~N}=25 \text { couples }\end{array}$ & \multicolumn{2}{|c|}{$\begin{array}{l}\text { Treatment as usual (TAU) } \\
\mathrm{N}=25 \text { couples }\end{array}$} \\
\hline $\begin{array}{l}10 \text { weeks of } \mathrm{CBCT} 囚-\mathrm{fC}, \\
\text { adapted versions of TPI, } \\
\text { PQ, SACiP; home-based } \\
\text { practice length etc. }\end{array}$ & \multicolumn{2}{|c|}{$\begin{array}{c}10 \text { weeks continuing } \\
\text { medical treatment / primary } \\
\text { health care / waiting for } \\
\text { starting individual therapy }\end{array}$} \\
\hline \multicolumn{3}{|c|}{$\begin{array}{l}\text { Day } 1 \text { T2: } \\
\text { - HDRS, BDI-II } \\
\text { - Same psychometric measures as pre-treatment } \\
\text { - } \text { Blood collection } \\
\text { - Start of ambulatory ECG for } 24 \text { hours recording }\end{array}$} \\
\hline
\end{tabular}

Day 2 T2: Laboratory assessment, positive social interaction (PSI)

- Eye-tracking, video-recording

- Saliva samples

- Psychometric measures

- End of 24 hours ECG recording

\begin{tabular}{|l|}
\hline 4-week follow-up FU1 - questionnaires (BDI-II, relationship quality etc.) \\
\begin{tabular}{|l|}
\hline 12-week follow-up FU2 - questionnaires (BDI-II, relationship quality etc.) \\
\hline
\end{tabular}
\end{tabular}

Figure 3 Flow diagram. BDI, Beck Depression Inventory, CBCT®-fC, "Cognitively-Based Compassion Training" for couples; HDRS, Hamilton Depression Rating Scale; PQ, Practice Quality, PSI, positive social interaction; SCID, Structured Clinical Interview for DSM; SACiP, Scale for the Multiperspective Assessment of General Change Mechanisms in Psychotherapy; TAU, treatment as usual; TPI, Therapeutic Presence Inventory.

compassion as an inner quality or skill can be trained based on the enlargement of feelings of endearment towards others and comes along with a variety of health benefits. ${ }^{79}$ The change process described here is rooted in Tibetan-Buddhist understanding-as the training itself is based on the so called lo-jong tradition, which means 'mind training' and is taught to cultivate compassion towards others not only close to us.

The model of how the intervention works is that change takes place in three steps: (1) starting at changing views by getting to know and to familiarise new perspectives receiving information, (2) based on that changing behaviour through conviction that comes about through critical and reflective thinking and then (3) embodied understanding takes place through thorough and repetitive, contemplative practice.

During the training process, several prerequisites and primary conditions are introduced in a stepwise manner, ultimately leading to compassion. "CBCT®" focuses on six essential key parts for the development of compassion: (1) developing attentional stability and clarity of the mind (focused attention and meditative concentration), (2) cultivating insight into the nature of mental experience (mindfulness with the focus to train non-judgment 
and non-reactivity with regard to the unfolding momentto-moment experiences), (3) cultivating self-compassion-recognising and understanding biased cognitions and reactions and enhancing self-efficacy, (4) developing impartiality by reflecting similarities with others such as the urge for well-being and happiness overcoming fixed categorisations of others into friends, enemies and strangers, (5) developing appreciation and affection for others by acknowledging our interdependent and interconnected nature and finally (6) developing empathy and realising engaged compassion-as an aspirational motivation and a readiness to altruistically act if possible and if needed. ${ }^{62}$ The intervention starts with an overview and basic instructions within the first session and end with a repetition, summary and take-home ideas for continuing practice during the last session. The first and the third module will be repeated once-resulting in a total of 10 sessions.

The main purpose of the programme is to develop compassion for oneself and others as well as to increase compassionate responses and behaviours-particularly in the context of relationships.

For enhancement of positive reciprocity between romantic partners, several exercises and home-based practices will be introduced that are based on couple communication training ${ }^{80-84}$ and on the protocol of the mindfulness-based relationship enhancement ${ }^{85}:$ (1) building mindful ability to talk, (2) building mindful ability to listen (without reacting initially), (3) appreciation in action-indulging the partner and (4) 'noticing, how the partner is doing something good for me'-gratefulness in action verbally/non-verbally. A dyadic empathy exercise will also been added, with regard to the manual of the 'Cognitive Behavioral Analysis System of Psychotherapy' for chronic major depression. ${ }^{56} 86$ Finally, the compassion meditation has been formalised as a dyadic exercise in addition to individual meditation. ${ }^{87}$

\section{Possible adverse events}

The intervention will be conducted with patients who are suffering from recurrent depressive disorder and their partners. We expect that the partner may show some degree of burden and individual distress. Risks or side effects of the intervention and psychometric assessment for couples are not known. The training can trigger negative emotional states. If negative states arise, they will be addressed in the group sessions or in supplemental individual or couple therapy sessions (maximum of three additional sessions).

The collection of a blood sample is usually associated with a very low risk. Slight pain may occur at the injection site or a bruise (blue spot) may appear which can be visible for a few days. In extremely rare cases, the formation of a blood clot (thrombosis), localised inflammation or infection at the injection site may also arise or permanent damage to blood vessels or nerves may happen. During the blood draws, the study physician is also present to identify any complications and side effects that may occur.

\section{Treatment as usual (TAU)}

Couples assigned to the TAU group will start (or continue) with TAU which will consist of receiving medical treatment and primary healthcare or waiting to start individual therapy (average waiting time 3 months) ${ }^{88}$ They will be asked to maintain their treatment plan during the study period of 10 weeks. Patients who start participating in regular psychotherapy treatment during the study period will be excluded from the analysis. All participants in the TAU group will be offered to participate in a CBCT-fC after the end of study (ie, after the second follow-up).

\section{Adherence}

Couples' compliance with the CBCT-fC meditations and exercises will be assessed with pen and paper questionnaires after each weekly in-house session using Therapeutic Presence Inventory ${ }^{89}$ (TPI, modified for the study), Practice Quality ${ }^{90}$ (PQ-M, adapted version of the Practice Quality-Mindfulness) and the Scale for the Multiperspective Assessment of General Change Mechanisms in Psychotherapy (SACiP). ${ }^{91}$ The CBCT-fC group will receive one text message four times weekly during the 10 -week period. This message will serve as a reminder for the meditation practice and home-based exercises and will also capture which meditations or practices participants completed and how long they practiced. Participants will be asked to indicate reasons innon-performance. Participants' emotional status will also be assessed via the Positive and Negative Affect Schedule (PANAS) ${ }^{92}$

The TAU control group will receive one text message per week during the same time period asking to indicate their emotional status.

\section{Primary outcome}

The primary outcome for the study is the reduction of depressive symptoms from baseline to postintervention, which will be measured with the HDRS observer-based rating instrument. The HDRS is a standardised rating scale that contains 21 items, scoring on 2-point to 5-point scales and will be administered twice throughout the study: at baseline and postintervention.

Psychometric properties are adequate with the internal consistency varying from 0.73 to $0.91 .^{93}$

\section{Secondary outcomes}

Self-rated depressive symptoms

In addition to the 21-item HDRS observer-based rating, we will also monitor changes in self-rated depression via the BDI-II at four measurement times (baseline, postintervention, follow-up I and II). The BDI-II is a standardised questionnaire comprising 21 items, with scoring on a 0-3 scale. The internal consistency varies from 0.89 to 0.93 and the retest reliability ranged from 0.80 to $0.82 .{ }^{94}$ 
Eye tracking during the positive social interaction paradigm (PSI)

During the interaction task (PSI), the female partner's eye movements will be monitored with a remote eye tracker (Tobii X2-60, sampling rate $60 \mathrm{~Hz}$ ) at $\mathrm{T} 1$ and T2. Total gaze duration in milliseconds will be assessed via real-time eye-tracking during a standardised PSI with the romantic partner. Raw coordinates of gaze and fixation will be mapped to the following predefined areas of interest: (1) eyes, (2) mouth, (3) other regions of the face and (4) off face and the areas of interest will be compared between depressed and controls as well as within depressed couples. In this study, we interpret eye-tracking data as a more objective proxy measure for social cognition processes with regard to emotion-related information processing biases. We expect that randomisation to CBCT-fC will result in increased maintenance of gaze towards the partner's face during the instructed interaction and thus, in a reduction of the social information processing biases accompanying the disorder.

\section{Cortisol and $\alpha$-amylase}

Cortisol and $\alpha$-Amylase will be collected as stress-sensitive biomarkers in sampling tubes for collection of saliva samples (RE69985 IBL International GmbH Hamburg, Germany) at four time-points $(-20 \mathrm{~min}$, pre-post, $+20 \mathrm{~min}$ relative to PSI) at T1 and T2. The samples will be stored at $-80^{\circ} \mathrm{C}$ and analysed in the in-house laboratory of the IMP, Heidelberg, Germany. These data will be analysed using area under the curve approach, ${ }^{95}$ comparing changes over time between the two study arms. We expect participants in the experimental group to experience a reduction in HPA-axis and SAM-axis reactivity during the PSI after the intervention.

\section{$\mathrm{IL}-1 \beta$ and IL-6}

IL-1 1 and IL- 6 will be measured in blood samples on lab day 1 at T1 and T2. The samples will be stored at $-80^{\circ} \mathrm{C}$ at the in-house lab and will then be sent to the Central Laboratory at Heidelberg University, where they will be processed by standard means (ie, high-sensitivity ELISA). We expect CBCT-fC to result in a reduction of the concentration level of both of the two proinflammatory cytokines in both members of a couple.

\section{Autonomic function (ECG)}

An ECG will be assessed with a one-lead ambulatory monitor (eMotion FAROS $180^{\circ}$ Mega Electronics, Kuopio. Finland) sampling at $1000 \mathrm{~Hz}$ for 24 hours recording at $\mathrm{T} 1$ and T2. Each individual will receive the monitor for 24 hours (attached with a chest belt) prior to the PSI, and until the end of the PSI assessment on the second day. Participants will be instructed in the handling of the device. The 24 hours ECG recording will be segmented in 5 min intervals as recommended by the Task Force Guidelines for HRV assessment. ${ }^{96}$ Beat-to-beat variation in the heart rate is mainly controlled by the ANS and permits determination of the relative contributions of sympathetic and parasympathetic activity underlying autonomic control of the heart. Here, rapid fluctuations in HR are due to vagal activity, while slower HR changes are a result of mixed influence of sympathetic (non-vagal) and parasympathetic activity. The following parameters will be derived for each segment using the software package 'RHRV' ${ }^{97}$ : (1) root mean square of successive differences (RMSSD), (2) successive normal-to-normal (NN) intervals that differ by more than $50 \mathrm{msec}$ (NN50), (3) the proportion of NN50 divided by total number of NNs (PNN50) indexing the rapid changes in HR and therefore vagal activity and (4) the SD of NN intervals (SDNN) with a resulting RR time series indexing mixed sympathetic and parasympathetic activity. ECG recordings will continue during the PSI, enabling us to analyse ANS reactivity to the interaction paradigm. We expect a stronger parasympathetic response to PSI after participation in CBCT-fC.

In an exploratory analysis, a two-stage approach will be used to estimate circadian variation parameters of cardiac autonomic function over a 24 hours period. Set in 2009 by the Research Domain Criteria initiative (RDoC) from the National Institute of Mental Health, a primary goal is to develop a classification system for mental health disorders, linking dimensions of psychopathology to neurobiological systems, including alterations in circadian rhythms. ${ }^{98}$ For the current study, a candidate system that might match these criteria is the central autonomic network (CAN). The CAN is widely involved in socioemotional regulatory processes. ${ }^{99} 100$ This network includes cortical components such as the medial, the prefrontal, the anterior cingulate and the insular cortex as well as several nuclei such as the paraventricular nucleus and the amygdala. The network is linked to the peripheral nervous system via the vagus nerve. In responses to emotional significant stimuli, autonomic output is modulated via the anterior cingulated cortex and its projections to the prefrontal cortex, amygdala, hypothalamus and brainstem. ${ }^{101}{ }^{102}$ Signals are transferred via the stellate ganglia and the vagus nerve to the sinoatrial node of the heart and modulates the heart rate. Therefore, activity in the neural structures involved in affective and autonomic regulation can be indexed non-invasively by measures of peripheral cardiac autonomic modulations, that is, vmHRV. ${ }^{103-105}$

Trigonometric regression models with ordinary least square estimations will be applied to each 24 hours period of $5 \mathrm{~min}$ segments, to estimate three individual level cosine function parameters, to capture individual CVPs in the time series of the following RMSSD segments: (1) MESOR defined as the rhythm adjusted 24 hours mean fitted to the data, (2) amplitude, defined as the distance between MESOR and the maximum of the cosine curve (ie, half the extent of rhythmic change in a cycle) and (3) acrophase, defined as the phase shift of amplitude from a given reference time point when the highest oscillation is reached (ie, time lag). ${ }^{106}$ This is assumed to be 24 hours period after visual inspection (for a more detailed explanation of underlying mathematics see Refinetti et $a l^{107}$ ). In a second step, these individual cosine function 
parameters will be forwarded as dependent variables to multivariate multiple regression models for simultaneous effect estimation of CBCT-fC on the circadian recovery profile of vagal activity. We will reduce alpha error by using a single regression model with simultaneous estimation of more than one outcome variable. We expect an increase in MESOR and Amplitude post-training.

\section{Epigenetics-SLC6A4 and OXTR}

The serotonin transporter gene SLC6A4 and the OXTR will be measured in blood samples on lab day 1 at T1 and T2. The PAXgene Blood RNA tubes are incubated at room temperature so that stabilisers in the tubes can become effective. The samples will be stored at $-80^{\circ} \mathrm{C}$ at the in-house lab and will then be sent to a certified laboratory, where they will be processed by standard means. We expect CBCT-fC to result in an alteration of the methylation pattern of both of the genes, focusing on specific CpG-sites in their promoter-regions.

\section{Statistical analysis and missing data}

All outcome data incorporating repeated observations (nested within individuals) will be analysed within 2-level hierarchical linear modelling. Repeated measures of the outcomes (eg, four observations for the BDI-II) will be modelled as level-1 variables. Group assignment (CBCT-fC vs TAU) will be regarded as a level-2 predictor (individual level), and the cross-level interaction will be tested for significant influence on the individual trajectories. Dependent variables that are measured simultaneously for both patients and their partner (eg, stress measures) will be analysed to determine dependencies within a couple, for example, by treating the dyad as a third hierarchy level. Type-I error probability will be set at $\alpha=0.05$ for all tests. Data based on an intention-to-treat approach will be compared with a completers-only dataset in the course of sensitivity analyses. Several strategies will be used to minimise the likelihood of missing data. We will clearly explain to couples what their efforts will be for the study before they agree to participate. We will also support couples by proactively manage their appointments of the pre-post assessments and other study requirements by sending reminder emails, texts and by making reminder phone calls. Training sessions will be offered in the evenings with a flexible start (between groups), to meet the needs of each training group. Completeness of questionnaire data will be closely monitored to avoid missing questionnaires. Participants will fill in their questionnaires at the IMP using a tablet PC. Study personnel will be available in the event of any questions or technical issues. Biomarker sampling will be monitored using standardised checklists, and we will note missing specimens as well as the reasons for their not being available.

Patient dropouts from the training will be closely monitored and reasons for leaving the study before the end of the protocol will be assessed to distinguish study-related reasons for attrition compared with other reasons and to improve study procedures.

\section{Sample size}

Power calculations were adapted for repeated-measures analysis of variance (ANOVA) enabling us to calculate the required sample size with $G^{*}$ Power. ${ }^{108}$ As multilevel modelling offers enhanced statistical power over a common ANOVA approach, the sample size calculated represents a conservative estimate. Power calculations are based on findings from van Aalderen et al. ${ }^{109}$ The authors investigated the effects of a mindfulness-based cognitive therapy for depressed patients within a large-scale RCT and found a medium sized effect of $d=0.53 \mathrm{SD}$ compared with a TAU condition on the HDRS (ie, the primary outcome of our study). Assuming a similar medium-sized effect $(f=0.25)$ when comparing CBCT-fC to TAU from pre-to-post intervention, power analysis with $\mathrm{G}^{*}$ Power suggests a required sample size of $n=40 \quad((1-\beta)=0.80, \rho=0.40)$. To accounting for $\mathrm{a} \sim 20 \%$ dropout, we plan to randomise $\mathrm{n}=50$ couples into the study.

\section{Data monitoring}

All training sessions will be videotaped and a selection will be reviewed by senior researchers. All PSI sessions will be videotaped and reviewed to ensure couples compliance to the PSI protocol. The laboratory sessions will be documented on checklists and reviewed by the senior staff. An experienced statistician will review all statistical analyses.

\section{DISCUSSION}

The SIDE study is the first investigation to examine multidimensional effects of a compassion-based training programme for couples with the female partner suffering from depression. The assessment protocol will allow for a comprehensive evaluation of naturalistic real-time interaction of romantic partners and for an integrative analysis of underlying biomarker change. In combination with self-report assessments and observer-based standard scales, our approach will enable us to advance the knowledge of the biopsychosocial processes involved in aetiology, progression and treatment of depressive disorders. ${ }^{110}$

Recent data suggest that depressed patients benefit less from the stress-reducing effects of PSIs and high-quality relationships than healthy individuals, both in a psychological and a biological way. Among others, social cognition processes and several markers of stress-physiology and immune-responses such as cortisol, alpha-amylase, cytokine IL-6 and IL-1ß and vmHRV as well as epigenetic marks (SLC6A4 and OXTR) might be altered while couples are instructed to positively interact with each other. Whether depressed female patients also display less active positive behaviour and an altered psychobiological response in real-time interaction remains to be examined.

With the SIDE study, we intend to address four innovative aspects of effectiveness research. First, the SIDE study will complement earlier preliminary evidence on the effects of CBCT on clinical improvements, ${ }^{67}$ 111-114 by addressing research gaps concerning the associations 
between compassion and depression. Second, and related to first point, specific aspects of the group intervention for enhancement of mindfulness and compassion on psychobiological concomitants will be elucidated. Third, the results will provide additional therapeutic tools to target a powerful mediator of health-the social relationship. Fourth, the male partner will be included in the group-based training taking into account his burden and addressing his needs, and thereby increase the chance for a better integration of interactional (ex)changes in daily routine.

\section{Possible limitations}

Although comparison with the TAU control group impedes the drawing of conclusions about the specificity of CBCT-fC over and above non-specific therapeutic factors, differences in measures of the extend of individuals' engagement in home practice (ie, time) may give some indications in that regard. Importantly, the training is thought to complement rather than to replace individual therapy. Therefore, we are particularly interested if the TAU plus CBCT-fC group improves with regard to the treatment outcomes via increased social functioning and reduced depressive and distress symptoms. In addition, both groups will have comparable TAU conditions and thus benefit from non-specific therapeutic factors, such as the therapeutic relationship and peer support. Furthermore, we will investigate the degree of active involvement with regard to the mindfulness and compassion meditations and dyadic exercises-both in-sessions and at home practice; allegiance will be controlled for potential bias effects.

\section{Ethics and dissemination}

Participants will be informed according to the Declaration of Helsinki. Medical staff will adhere to the professional code of conduct for doctors in Baden-Württemberg, Germany. Study participation is completely voluntary. Detailed written and oral information on study aims, procedure, benefits and risks will be provided (see online supplementary appendixes 2-5). After written informed consent, eligible participants will be enrolled. Full participation in the study assessments will be financially compensated. The IMP will fully cover costs for the CBCT-fC. In case any changes have to be made with regard to the study protocol, these will be communicated with the ethics committee. Results will be presented in international, peer-reviewed journals and on conferences in the field of clinical psychology and psychiatry.

\footnotetext{
Author affiliations

${ }^{1}$ Institute of Medical Psychology, Center for Psychosocial Medicine, University Hospital Heidelberg, Heidelberg, Germany

${ }^{2}$ Department of Psychosomatic Medicine and Psychotherapy, University Clinic Ulm, Ulm, Germany

${ }^{3}$ Department of Religion, Emory-Tibet Partnership, Center for Contemplative Science and Compassion-Based Ethics, Emory College, Emory University, Atlanta, Georgia, USA

${ }^{4}$ Emory-Tibet Partnership, Center for Contemplative Science and CompassionBased Ethics, CBCT® Teacher Training, Emory University, Atlanta, Georgia, USA
}

${ }^{5}$ College of Nursing, University of Arizona, Tucson, Arizona, USA

${ }^{6}$ Department of Psychiatry, College of Medicine, University of Arizona, Tucson, Arizona, USA

${ }^{7}$ Department of Psychology, College of Science, University of Arizona, Tucson, Arizona, USA

Acknowledgements We would like to acknowledge the Mind and Life Institute providing financial support in part for the preparation phase in form of the Francisco J Varela Award, which Dr Aguilar-Raab received in order to modify and extend the CBCT protocol to suit couples in close collaboration with experts in the field. Furthermore, we thank the Institute for Medical Psychology, University Hospital Heidelberg and staff members for providing financial and infrastructural support. CA- $\mathrm{R}$ is supported by the The Olympia Morata Programme of the Heidelberg University and MNJ and MW are supported by the Physician-Scientist-Program of the Medical Faculty at Heidelberg University. We acknowledge financial support by Deutsche Forschungsgemeinschaft within the funding programme Open Access Publishing, by the Baden-Württemberg Ministry of Science, Research and the Arts and by Ruprecht-Karls-Universität Heidelberg.

Contributors CA-R and MNJ drafted the first version of the manuscript sharing the first authorship as they contributed equally. MT and JB supported this process. BD, LTN, TH and TWWP delivered feedback on a first version of the paper-LTN and TH focusing especially on the CBCT-fC part. CA-R, MNJ, MW, FW and TWWP critically revised the second version of the manuscript for important intellectual content with regard to psychobiological assessments, and additionally TWWP did the English copyediting. While revising the manuscript, MS was engaged specifically with rewriting the parts on epigenetics. CA-R, MNJ and BD contributed to the design of the study. All authors have approved the final version of the manuscript.

Funding The study is mainly funded by the Institute of Medical Psychology, University Hospital Heidelberg and partly by the Mind and Life Organization as well as by the Deutsche Gesellschaft für Systemische Therapie, Beratung und Familientherapie. Further funding is pending.

Competing interests None declared.

Patient consent Not required.

Ethics approval Ethics Committee of the Medical Faculty Heidelberg, Heidelberg University, Germany (S-021/2016).

Provenance and peer review Not commissioned; externally peer reviewed.

Data sharing statement Research data will be made available for future research by other researchers anonymously via the Competence Centre for Research Data (Heidelberg University) using the platform heiDATA (the university's research data repository) in line with its Research Data Policy adopted by Heidelberg University: http://www.data.uni-heidelberg.de/services.html. Confidential information of all participants is subject to data protection. Data will only be passed on to third parties in a deidentified format (ie, all protected health information removed).

Open access This is an open access article distributed in accordance with the Creative Commons Attribution Non Commercial (CC BY-NC 4.0) license, which permits others to distribute, remix, adapt, build upon this work non-commercially, and license their derivative works on different terms, provided the original work is properly cited, appropriate credit is given, any changes made indicated, and the use is non-commercial. See: http://creativecommons.org/licenses/by-nc/4.0/.

\section{REFERENCES}

1. Kessler RC, Bromet EJ. The epidemiology of depression across cultures. Annu Rev Public Health 2013;34:119-38.

2. Carney RM, Freedland KE, Veith RC. Depression, the autonomic nervous system, and coronary heart disease. Psychosom Med 2005;67 Suppl 1:S29-S33.

3. Vaillant GE, Mukamal K. Successful Aging. Am J Psychiatry 2001;158:839-47.

4. Beach S, Wamboldt MZ, Kaslow N, et al. Relational processes and DSM-V: Neuroscience, assessment, prevention, and treatment. Arlington, VA: American Psychiatric Association Press, 2006.

5. Holt-Lunstad J. Why social relationships are important for physical health: a systems approach to understanding and modifying risk and protection. Annu Rev Psychol 2018;69:437-58.

6. Ditzen B, Heinrichs M. Psychobiology of social support: the social dimension of stress buffering. Restor Neurol Neurosci 2014;32:149-62. 
7. Robles TF, Slatcher RB, Trombello JM, et al. Marital quality and health: a meta-analytic review. Psychol Bull 2014;140:140-87.

8. Hirschfeld RM, Montgomery SA, Keller MB, et al. Social functioning in depression: a review. J Clin Psychiatry 2000;61:268-75.

9. Fink BC, Shapiro AF. Coping mediates the association between marital instability and depression, but not marital satisfaction and depression. Couple and Family Psychology: Research and Practice 2013;2:1-13.

10. Rehman US, Gollan J, Mortimer AR. The marital context of depression: research, limitations, and new directions. Clin Psychol Rev 2008;28:179-98.

11. Overall NC, Hammond MD. Biased and accurate: depressive symptoms and daily perceptions within intimate relationships. Pers Soc Psychol Bull 2013;39:636-50.

12. Kupferberg A, Hager OM, Fischbacher U, et al. Testing the social competition hypothesis of depression using a simple economic game. BJPsych Open 2016;2:163-9.

13. Armstrong $T$, Olatunji BO. Eye tracking of attention in the affective disorders: A meta-analytic review and synthesis. Clin Psychol Rev 2012;32:704-23.

14. Joormann J, Gotlib IH. Selective attention to emotional faces following recovery from depression. J Abnorm Psychol 2007;116:80-5

15. Sears CR, Newman KR, Ference JD, et al. Attention to emotional images in previously depressed individuals: an eye-tracking study. Cognit Ther Res 2011;35:517-28.

16. Herbert J. Cortisol and depression: three questions for psychiatry. Psychol Med 2013;43:449-69.

17. Burke HM, Davis MC, Otte C, et al. Depression and cortisol responses to psychological stress: A meta-analysis. Psychoneuroendocrinology 2005;30:846-56.

18. Booij SH, Bos EH, Bouwmans ME, et al. Cortisol and $\alpha$-amylase secretion patterns between and within depressed and nondepressed individuals. PLoS One 2015;10:e0131002.

19. Schumacher S, Kirschbaum C, Fydrich T, et al. Is salivary alphaamylase an indicator of autonomic nervous system dysregulations in mental disorders?-a review of preliminary findings and the interactions with cortisol. Psychoneuroendocrinology 2013;38:729-43.

20. Kemp AH, Quintana DS. The relationship between mental and physical health: insights from the study of heart rate variability. Int $J$ of Psychophysiology 2013;89:288-96.

21. Miller $\mathrm{AH}$, Raison CL. The role of inflammation in depression: from evolutionary imperative to modern treatment target. Nat Rev Immunol 2016;16:22-34.

22. Kang HJ, Kim JM, Stewart R, et al. Association of SLC6A4 methylation with early adversity, characteristics and outcomes in depression. Prog Neuropsychopharmacol Biol Psychiatry 2013;44:23-8.

23. Holsboer F. The corticosteroid receptor hypothesis of depression. Neuropsychopharmacology 2000;23:477-501.

24. Palazidou E. The neurobiology of depression. Br Med Bull 2012;101:127-45

25. Morris MC, Compas BE, Garber J. Relations among posttraumatic stress disorder, comorbid major depression, and HPA function: a systematic review and meta-analysis. Clin Psychol Rev 2012;32:301-15.

26. Stetler C, Miller GE. Depression and hypothalamic-pituitary-adrena activation: a quantitative summary of four decades of research. Psychosom Med 2011;73:114-26.

27. Bagley SL, Weaver TL, Buchanan TW. Sex differences in physiological and affective responses to stress in remitted depression. Physiol Behav 2011;104:180-6.

28. Tanaka Y, Ishitobi Y, Maruyama Y, et al. Salivary alpha-amylase and cortisol responsiveness following electrical stimulation stress in major depressive disorder patients. Prog Neuropsychopharmacol Biol Psychiatry 2012;36:220-4.

29. Bosch JA, Veerman ECI, de Geus EJ, et al. $\alpha$-Amylase as a reliable and convenient measure of sympathetic activity: don't start salivating just yet!. Psychoneuroendocrinology 2011;36:449-53.

30. Nater UM, Rohleder N. Salivary alpha-amylase as a non-invasive biomarker for the sympathetic nervous system: Current state of research. Psychoneuroendocrinology 2009;34:486-96.

31. Rohleder N, Chen E, Wolf JM, et al. The psychobiology of trait shame in young women: Extending the social self preservation theory. Health Psychology 2008;27:523-32.

32. Verkuil B, Brosschot JF, Marques AH, et al. Gender differences in the impact of daily sadness on $24-\mathrm{h}$ heart rate variability. Psychophysiology 2015;52:1682-8.

33. Jarczok MN, Aguilar-Raab C, Koenig J, et al. The Heart's rhythm ' $n$ ' blues: Sex differences in circadian variation patterns of vagal activity vary by depressive symptoms in predominantly healthy employees. Chronobiol Int 2018:1:14

34. Jarczok MN, Koenig J, Shively CA, et al. Behavioral depression is associated with increased vagally mediated heart rate variability in adult female cynomolgus monkeys (Macaca fascicularis). Int $\mathrm{J}$ Psychophysiol 2017.

35. Maletic V, Robinson M, Oakes T, et al. Neurobiology of depression: an integrated view of key findings. Int J Clin Pract 2007;61:2030-40.

36. Pace TW, Mletzko TC, Alagbe O, et al. Increased stress-induced inflammatory responses in male patients with major depression and increased early life stress. Am J Psychiatry 2006;163:1630-3.

37. Raison CL, Capuron L, Miller AH. Cytokines sing the blues: inflammation and the pathogenesis of depression. Trends Immunol 2006;27:24-31.

38. Menke A, Binder EB. Epigenetic alterations in depression and antidepressant treatment. Dialogues Clin Neurosci 2014;16:395-404.

39. Alasaari JS, Lagus M, Ollila HM, et al. Environmental stress affects DNA methylation of a CpG rich promoter region of serotonin transporter gene in a nurse cohort. PLoS One 2012;7:e45813.

40. Klengel T, Pape J, Binder EB, et al. The role of DNA methylation in stress-related psychiatric disorders. Neuropharmacology 2014;80:115-32.

41. Voisey J, Young RM, Lawford BR, et al. Progress towards understanding the genetics of posttraumatic stress disorder. $J$ Anxiety Disord 2014;28:873-83.

42. Jack A, Connelly JJ, Morris JP. DNA methylation of the oxytocin receptor gene predicts neural response to ambiguous social stimuli. Front Hum Neurosci 2012;6:1-7.

43. Walum H, Lichtenstein P, Neiderhiser JM, et al. Variation in the oxytocin receptor gene is associated with pair-bonding and social behavior. Biol Psychiatry 2012;71:419-26.

44. Woods R, Bedard M, McQuaid RJ, et al. Rejection sensitivity and multiple group memberships: The moderating role of an oxytocin receptor gene polymorphism. Soc Neurosci 2018;13:1-9.

45. Booij L, Szyf M, Carballedo A, et al. DNA methylation of the serotonin transporter gene in peripheral cells and stress-related changes in hippocampal volume: a study in depressed patients and healthy controls. PLoS One 2015;10:e0119061.

46. Sugawara $H$, Bundo $M$, Asai T, et al. Effects of quetiapine on DNA methylation in neuroblastoma cells. Prog Neuropsychopharmacol Biol Psychiatry 2015;56:117-21.

47. Zannas AS, West AE. Epigenetics and the regulation of stress vulnerability and resilience. Neuroscience 2014;264:157-70.

48. Szyf M, Tang YY, Hill KG, et al. The dynamic epigenome and its implications for behavioral interventions: a role for epigenetics to inform disorder prevention and health promotion. Trans/ Behav Med 2016;6:55-62.

49. Roberts S, Lester KJ, Hudson JL, et al. Serotonin tranporter methylation and response to cognitive behaviour therapy in children with anxiety disorders. Trans/ Psychiatry 2014;4:e444.

50. Zhao J, Goldberg J, Bremner JD, et al. Association between promoter methylation of serotonin transporter gene and depressive symptoms: a monozygotic twin study. Psychosom Med 2013;75:523-9.

51. Shapiro SL, Carlson LE, Astin JA, et al. Mechanisms of mindfulness. $J$ Clin Psychol 2006;62:373-86.

52. Kabat-Zinn J. Full catastrophe living: using the wisdom of your mind and body to face stress, pain, and illness. New York: Delacorte, 1990.

53. Bishop SR, Lau M, Shapiro S, et al. Mindfulness: A Proposed Operational Definition. Clinical Psychology: Science and Practice 2004;11:230-41.

54. Grossman P, Niemann L, Schmidt S, et al. Mindfulness-based stress reduction and health benefits. J Psychosom Res 2004;57:35-43.

55. Kabat-Zinn J. Mindfulness-Based Interventions in Context: Past, Present, and Future. Clinical Psychology: Science and Practice 2003:10:144-56.

56. Michalak J, Schultze M, Heidenreich T, et al. A randomized controlled trial on the efficacy of mindfulness-based cognitive therapy and a group version of cognitive behavioral analysis system of psychotherapy for chronically depressed patients. J Consult Clin Psychol 2015;83:951-63.

57. Keng SL, Smoski MJ, Robins CJ. Effects of mindfulness on psychological health: a review of empirical studies. Clin Psychol Rev 2011;31:1041-56.

58. Nila K, Holt DV, Ditzen B, et al. Mindfulness-based stress reduction (MBSR) enhances distress tolerance and resilience through changes in mindfulness. Ment Health Prev 2016;4:36-41.

59. Segal ZV, Williams JMG, Teasdale JD. Mindfulness-based cognitive therapy for depression. 1 ed. New York: Guilford Press, 2002. 
60. Khoury B, Lecomte T, Fortin G, et al. Mindfulness-based therapy: A comprehensive meta-analysis. Clin Psychol Rev 2013;33:763-71.

61. Ozawa-de Silva B, Negi LT. Cognitively-Based Compassion Training: Protocol and key concepts. In: Bolz M, Singer T, Compassion: bridging theory and practice. Leipzig: Max Planck Institute for Human Cognitive and Brain Sciences, 2013:416-38.

62. Dodds SE, Pace TWW, Bell ML, et al. Feasibility of CognitivelyBased Compassion Training (CBCT) for breast cancer survivors: a randomized, wait list controlled pilot study. Supportive Care in Cancer 2015;23:3599-608.

63. Desbordes G, Negi LT, Pace TW, et al. Effects of mindful-attention and compassion meditation training on amygdala response to emotional stimuli in an ordinary, non-meditative state. Front Hum Neurosci 2012;6:292.

64. Strauss C, Lever Taylor B, Gu J, et al. What is compassion and how can we measure it? A review of definitions and measures. Clin Psychol Rev 2016;47:15-27.

65. Fredrickson BL, Cohn MA, Coffey KA, et al. Open hearts build lives: positive emotions, induced through loving-kindness meditation, build consequential personal resources. J Pers Soc Psychol 2008;95:1045-62.

66. Hutcherson CA, Seppala EM, Gross JJ. Loving-kindness meditation increases social connectedness. Emotion 2008;8:720-4.

67. Pace TWW, Negi LT, Adame DD, et al. Effect of compassion meditation on neuroendocrine, innate immune and behavioral responses to psychosocial stress. Psychoneuroendocrinology 2009;34:87-98.

68. Carson JW, Carson KM, Gil KM, et al. Mindfulness-based relationship enhancement (MBRE) in couples. Baer RA, ed. Mindfulness-based treatment approaches: Clinician's guide to evidence base and applications. Burlington, MA: Academic Press, 2006:309-31.

69. Wachs K, Cordova JV. Mindful relating: exploring mindfulness and emotion repertoires in intimate relationships. J Marital Fam Ther 2007;33:464-81.

70. Barnes S, Brown KW, Krusemark E, et al. The role of mindfulness in romantic relationship satisfaction and responses to relationship stress. J Marital Fam Ther 2007;33:482-500.

71. Neff KD. The Development and Validation of a Scale to Measure Self-Compassion. Self and Identity 2003;2:223-50.

72. Yarnell LM, Neff KD. Self-compassion, Interpersonal Conflict Resolutions, and Well-being. Self and Identity 2013;12:146-59.

73. Falkai P, Wittchen H-U. Diagnostisches und Statistisches Manual Psychischer Störungen - DSM-5. Göttingen: Hogrefe, 2014:1298.

74. Hamilton M. A rating scale for depression. Journal of Neurology, Neurosurgery \& Psychiatry 1960;23:56-62.

75. Beck AT, Steer RA, Ball R, et al. Comparison of Beck Depression Inventories -IA and -II in psychiatric outpatients. J Pers Assess 1996;67:588-97.

76. Dgppn, Bäk KBV. S3-Leitlinie/Nationale VersorgungsLeitlinie Unipolare Depression. 2 Aufl. ed: Langfassung, 2015.

77. Hahlweg K, Kraemer M, Schindler L, et al. Partnerschaftsprobleme: Eine empirische Analyse. Z Klin Psychol 1980;9:159-69.

78. Altman DG, Schulz KF, Moher D, et al. CONSORT GROUP (Consolidated Standards of Reporting Trials). The revised CONSORT statement for reporting randomized trials: explanation and elaboration. Ann Intern Med 2001:134:663-94.

79. Cohen S. Social relationships and health. Am Psychol 2004:59:676-84.

80. Beach SR, Sandeen EE, O'leary KD. Depression in Marriage. New York: Guilford Press, 1990.

81. Cohen S, Daniel O'Leary K, Foran HM, et al. Mechanisms of Change in Brief Couple Therapy for Depression. Behav Ther 2014;45:402-17.

82. Hahlweg K, Baucom DH. Partnerschaft und Sörung. 1 ed: Hogrefe, 2008.

83. Kröger C, Heinrichs N, Hahlweg K. In: Hautzinger M, Pauli P, eds. Kompetenz-, Kommunikations- und Problemlösetraining [Competence training, communication training, and problem-solving training]. Göttingen: Hofgrefe, 2009.

84. Schindler L, Hahlweg K, Revenstorf D. Partnerschaftsprobleme: Diagnose und Therapie. Handbuch für den Therapeuten. 2 ed. Berlin: Springer, 2006.

85. Carson JW, Carson KM, Gil KM, et al. Mindfulness-based relationship enhancement. Behav Ther 2004;35:471-94.

86. McCullough Jr J. Treatment for chronic depression: CBASP. New York: Guilford, 2000.

87. Singer T, Bornemann B. The ReSource training protocol. In: Singer T, Bornemann B, eds. Compassion: Bridging practice and science. Leipzig: Max Planck Institute for Human Cognitive and Brain Sciences, 2013:452-65.
88. Bundespsychotherapeutenkammer. BPtK -Studie zu Wartezeiten in der ambulanten psychotherapeutischen Versorgung - Umfrage der Landespsychotherapeutenkammern und der BPtK. 2011 www.bptk. de.

89. Geller SM, Greenberg LS, Watson JC. Therapist and client perceptions of therapeutic presence: the development of a measure. Psychother Res 2010;20:599-610.

90. Del Re AC, Flückiger C, Goldberg SB, et al. Monitoring mindfulness practice quality: an important consideration in mindfulness practice. Psychother Res 2013;23:54-66.

91. Mander J, Schlarb A, Teufel M, et al. The Individual Therapy Process Questionnaire: Development and Validation of a Revised Measure to Evaluate General Change Mechanisms in Psychotherapy. Clin Psychol Psychother 2015;22:328-45.

92. Watson D, Clark LA, Tellegen A. Development and validation of brief measures of positive and negative affect: The PANAS scales. J Pers Soc Psychol 1988;54:1063-70.

93. Baumann U. Methodische Untersuchungen zur HamiltonDepression-Skala. Archiv $f \otimes r$ Psychiatrie und Nervenkrankheiten 1976;222:359-75.

94. Herzberg PY, Goldschmidt S, Heinrichs N. Beck DepressionsInventar (BDI-II). Revision: TBS-TK Rezesion, 2008.

95. Pruessner JC, Kirschbaum C, Meinlschmid G, et al. Two formulas for computation of the area under the curve represent measures of total hormone concentration versus time-dependent change. Psychoneuroendocrinology 2003;28:916-31.

96. Heart rate variability: standards of measurement, physiological interpretation and clinical use. Task Force of the European Society of Cardiology and the North American Society of Pacing and Electrophysiology. Circulation 1996;93:1043-65.

97. Garcia CA, Otero A, Presedo J, et al. A software toolkit for nonlinear Heart Rate Variability analysis. Computing in Cardiology Conference 2013.

98. National Institute of Mental Health. Research Domain Criteria (RDoC). 2013 https://www.nimh.nih.gov/research-priorities/rdoc/ development-and-definitions-of-the-rdoc-domains-and-constructs. shtml (accessed 02.02.2017).

99. Riganello F, Dolce G, Sannita W. Heart rate variability and the central autonomic network in the severe disorder of consciousness. $J$ Rehabil Med 2012;44:495-501.

100. Thayer JF, Åhs F, Fredrikson M, et al. A meta-analysis of heart rate variability and neuroimaging studies: Implications for heart rate variability as a marker of stress and health. Neuroscience \& Biobehavioral Reviews 2012;36:747-56.

101. Critchley HD, Mathias CJ, Josephs O, et al. Human cingulate cortex and autonomic control: converging neuroimaging and clinical evidence. Brain 2003;126:2139-52.

102. Holzman JB, Bridgett DJ. Heart rate variability indices as biomarkers of top-down self-regulatory mechanisms: A meta-analytic review. Neuroscience \& Biobehavioral Reviews 2017;74:233-55.

103. Bassett $D$. A literature review of heart rate variability in depressive and bipolar disorders. Australian \& New Zealand Journal of Psychiatry 2016;50:511-9.

104. Tbj K, Lai CJ, Huang YT, et al. Regression analysis between heart rate variability and baroreflex-related vagus nerve activity in rats. $J$ Cardiovasc Electrophysiol 2005;16:864-9.

105. Thayer JF, Lane RD. Claude Bernard and the heart-brain connection: Further elaboration of a model of neurovisceral integration. Neuroscience \& Biobehavioral Reviews 2009;33:81-8.

106. Fernández JR, Hermida RC, Mojón A. Chronobiological analysis techniques. Application to blood pressure. Philos Trans A Math Phys Eng Sci 2009;367:431-45.

107. Refinetti R, Cornélissen G, Halberg F. Procedures for numerical analysis of circadian rhythms. Biol Rhythm Res 2007;38:275-325.

108. Faul $F$, Erdfelder $E$, Lang AG, et al. G*Power 3: a flexible statistical power analysis program for the social, behavioral, and biomedical sciences. Behav Res Methods 2007;39:175-91.

109. van Aalderen JR, Donders AR, Giommi F, et al. The efficacy of mindfulness-based cognitive therapy in recurrent depressed patients with and without a current depressive episode: a randomized controlled trial. Psychol Med 2012;42:989-1001.

110. National Institute of Mental Health. Research Domain Criteria. 2017 http://www.nimh.nih.gov/research-priorities/rdoc/development-anddefinitions-of-the-rdoc-domains-and-constructs.shtml.

111. Pace TWW, Negi LT, Dodson-Lavelle B, et al. Engagement with cognitively-based compassion training is associated with reduced salivary C-reactive protein from before to after training in foster care program adolescents. Psychoneuroendocrinology 2013;38:294-9.

112. Reddy SD, Negi LT, Dodson-Lavelle B, et al. Cognitive-based compassion training: a promising prevention strategy for at-risk adolescents. J Child Fam Stud 2013:22:219-30. 
113. Shonin E, Van Gordon W, Compare A, et al. Buddhist-derived loving-kindness and compassion meditation for the treatment of psychopathology: a systematic review. Mindfulness 2015;6:1161-80.

114. Pace TWW, Negi LT, Sivilli TI, et al. Innate immune, neuroendocrine and behavioral responses to psychosocial stress do not predict subsequent compassion meditation practice time. Psychoneuroendocrinology 2010;35:310-5.

115. Schulz U, Schwarzer R. Soziale Unterstützung bei der Krankheitsbewältigung: Die Berliner Social Support Skalen (BSSS) Diagnostica 2003;49:73-82.

116. Sprecher S, Fehr B. Compassionate love for close others and humanity. J Soc Pers Relat 2005.

117. Aguilar-Raab C, Grevenstein D, Schweitzer J. Measuring Social Relationships in Different Social Systems: The Construction and Validation of the Evaluation of Social Systems (EVOS) Scale. PLoS One 2015;10:e0133442-e42.

118. Aguilar-Raab C, Grevenstein D, Gotthardt L, et al. Changing Me, Changing Us: Relationship Quality and Collective Efficacy as Major Outcomes in Systemic Couple Therapy. Fam Process 2018;57:342-58.

119. Russell DW. UCLA Loneliness Scale (Version 3): reliability, validity, and factor structure. J Pers Assess 1996;66:20-40.

120. Doring N, Bortz J. Psychometrische Einsamkeitsforschung. Deutsche Neukonstruktion der UCLA Loneliness Scale. Diagnostica 1993;39:224-39.

121. Baer RA, Smith GT, Allen KB. Assessment of mindfulness by selfreport: the Kentucky inventory of mindfulness skills. Assessment 2004:11:191-206.

122. Ströhle G, Nachtigall C, Michalak J, et al. Die Erfassung von Achtsamkeit als mehrdimensionales Konstrukt: Die deutsche
Version des Kentucky Inventory of Mindfulness Skills (KIMS-D). Z Klin Psychol Psychother 2010;39:1-12.

123. Hahlweg K. Konstruktion und Validierung des Partnerschaftsfragebogens PFB. Z Klin Psychol 1979;8:17-40.

124. Spitzer RL, Kroenke K, Williams JB. Validation and utility of a selfreport version of PRIME-MD: the PHQ primary care study. Primary Care Evaluation of Mental Disorders. Patient Health Questionnaire. JAMA 1999;282:1737-44.

125. Löwe B, Spitzer RL, Zipfel S, et al. PHQ-D: Gesundheitsfragebogen für Patienten. Pfizer: Karlsruhe, 2002.

126. Hendrick SS. A Generic Measure of Relationship Satisfaction. J Marriage Fam 1988;50:93-8.

127. Hupfeld J, Ruffieux N. Validierung einer deutschen Version der SelfCompassion Scale (SCS-D). Zeitschrift für Klinische Psychologie und Psychotherapie 2011;40:115-23.

128. Schulz P, Schlotz W, Becker P. Trier Inventar zum chronischen Stress (TICS. Göttingen: Hogrefe, 2004.

129. Bernstein DP, Fink L. Childhood Trauma Questionnaire: A retrospective self-report manual. San Antonio: TX: The Psychological Corporation, 1998.

130. Thomas A, Brähler E, Strauß B. IIP-32: Entwicklung, Validierung und Normierung einer Kurzform des Inventars zur Erfassung interpersonaler Probleme. Diagnostica 2011;57:68-83.

131. Horowitz LM, Rosenberg SE, Baer BA, et al. Inventory of interpersonal problems: psychometric properties and clinica applications. J Consult Clin Psychol 1988;56:885-92.

132. Wittchen $\mathrm{H}-\mathrm{U}$, Wunderlich U, Gruschwitz S, et al. Strukturiertes Klinisches Interview für DSM-IV Achse I: Psychische Störungen. Göttingen: Hogrefe, 1997. 